\section{Relationship between Cytochrome P450 G1347A Gene Polymorphism and Risk of Ischemic Stroke in North Indian Population: A Case-Control Study}

\section{Abstract}

Objective: Present study was taken up to establish the association between CYP4F2 G1347A polymorphism and risk of ischemic stroke (IS) in a North Indian population.

Methods: In a hospital-based case-control study, 250 cases and 250 age and sex matched control subjects were recruited from Outpatient Department of Neurology, All India Institute of Medical Sciences, New Delhi, India. Polymerase chain reaction - Restriction fragment length polymorphism (PCR-RFLP) was used for genotyping. Data were analyzed using STATA software, Version 13.

Results: The mean age of IS patients were $52.83 \pm 12.59$ years and in control group were $50.97 \pm 12.70$ years. Genotypic frequency distributions were in accordance with Hardy Weinberg Equilibrium (HWE) in both cases and controls. Conditional logistic regression analysis showed an independent association between CYP450 G1347A gene polymorphism with the risk of IS under dominant model (OR 2.05; $95 \% \mathrm{Cl} 1.18$ to 3.56). Analysis based on Trial of Org 10172 in Acute Stroke Treatment (TOAST) classification discerned a significant association with Large Vessel Disease (LVD) subtype of IS in both the unadjusted (OR, 2.5; 95\% Cl 1.49 to 4.20 ) and adjusted (OR, 3.32; 95\% $\mathrm{Cl} 1.72$ to 6.43 ) analysis and a significant association with Small Vessel Disease (SVD) subtype of IS after the adjusted analysis (OR, 2.43; 95\% $\mathrm{Cl} 1.14$ to 5.16 ) under recessive model.

Conclusion: Present study suggests that CYP4F2 G1347A polymorphism may be an important risk factor for IS mainly for LVD subtype of IS. Prospective studies with large sample size are needed to confirm the present findings.

Keywords: Ischemic stroke; Single nucleotide polymorphism; Cytochrome P450; North India

\section{Ram Sagar' ${ }^{1}$ Amit Kumar', Shubham Misra ${ }^{1}$, Pradeep Kumar', Ritesh Raj', Arti Gulati ${ }^{2}$ and Kameshwar Prasad ${ }^{* 1}$}

1 Department of Neurology, All India Institute of Medical Sciences, New Delhi, India

2 Clinical Epidemiology Unit, All India Institute of Medical Sciences, New Delhi, India

\section{*Corresponding author:}

Dr. Kameshwar Prasad

\section{kp0704@gmail.com}

Professor \& Head, Room No. 702, 7th Floor, Department of Neurology, Chief of the Neurosciences Centre, All India Institute of Medical Sciences, Ansari Nagar, New Delhi, India.

Tel: +91-11-26593497, 26588979

Fax: +91-11-26588663, 26588979

Citation: Sagar R, Kumar A, Misra S, Kumar P, Raj R, et al. (2019) Relationship between Cytochrome P450 G1347A Gene Polymorphism and Risk of Ischemic Stroke in North Indian Population: A Case-Control Study. J Neurol Neurosci Vol.10 No.02:297.

Received: March 02, 2019; Accepted: March 25, 2019; Published: April 02, 2019

\section{Introduction}

Stroke is a crucial, devastating neurological disorder which may lead to permanent disability or death. It has been predicted that there will be $>200$ million Disability Adjusted Life Years (DALYs) lost, 70 million survivors and 20 million deaths after stroke by 2030 across the world [1]. Stroke has been recognized as an intricate, multifactorial and polygenic neurological disorder occurring from the environmental, genetic and combination of vascular risk factors. Heritability presumes the ischemic stroke
(IS) varies from 17 to $38 \%[2,3]$. The genome wide association studies (GWAS) have replicated few genetic loci associated with specific IS subtypes. This has guided the concept that genetic risk varies in different subtypes of IS. Several candidate gene association studies have been conducted thus far to identify the relationship of the genetic variants and risk alleles with a particular disease [4].

The gene cytochrome $P 450$ (CYP4F2) is predominately expressed in cerebral arteries of human, which encodes an enzyme 
$\omega$-hydroxylase that accelerate the metabolism of major membrane fatty acid i.e., arachidonic acid to 20-hydroxyeicosatetraenoic acid which have crucial contribution for maintenance of vascular constriction in skeletal muscle arterioles, coronary, pulmonary circulation, renal and cerebral arteries [5,6]. 20-HETE is a strong vasoconstrictor and can stimulate the myogenic vasoconstriction of cerebral arterial muscle cells $[7,8]$. A study showed higher level of 20-HETE in plasma after the middle cerebral artery occlusion of stroke and suggested blockage of the formation of 20-HETE may be useful for the treatment of IS [9]. Evidence from literature has shown that CYP gene and altered renal 20-HETE content have a vital role in hypertension and IS.

It's a subfamily of CYP4F2 enzyme involves in metabolism of Leukotriene B4 (a potent mediator of inflammation) and 20HETE. Gene is located on the chromosome 19p.13.11 which reduces the $\omega$-hydroxylase that accelerate the metabolism of LTB4, tocopherol and arachinodonic acid. Candidate gene studies have shown that polymorphism G1347A (rs2108622) leads to the substitution of Valine to Methionine which leads to reduced AA metabolizing activity. Recent meta-analysis has shown that CYP4F2 gene variation enhances the risk for ischemic stroke [10]. However, due to modest effect of SNPs in phenotype, studies with adequate number of samples from different populations are needed to be done for the validation of findings. Therefore, we aim to study the relationship between CYP450 (G1347A) gene polymorphism with the risk of IS in North Indian population.

\section{Materials and Methods}

\section{Study participants}

This was an age and sex matched case-control study, undertaken (November 2012 to October 2014) in tertiary referral hospital in India (Neurosciences Centre, All India Institute of Medical Sciences (AlIMS), New Delhi). A total of 250 patients with 250 controls were enrolled after screening the eligibility criteria $[11,12]$. Local Institutional Ethics Committee approval was taken. All patients underwent a detailed clinical evaluation [13]. Trial of Org 10172 in Acute Stroke treatment (TOAST) criteria was used to further classification of IS [14]. Definition of demographic variables and risk factors were same in the earlier published study Kumar et al. [15].

\section{Laboratory investigations}

Peripheral blood sample $(4 \mathrm{ml})$ was drawn from all the study participants for DNA extraction using phenol chloroform isolation method.

\section{Genotype determination}

Cytochrome P450 gene polymorphism was determined using PCR-RLFP method. Primers were designed through Primer-3 online software for the single nucleotide polymorphism. G1347A regions were amplified in the TaKaRa PCR Thermal Cycler Dice (TAKARA BIO INC) using primer sequences: Forward 5'ATCAACCCGTTCCCACCT3' and Reverse 5'ACATTGTGCTCCCAGACG3' at annealing temperature $59.8^{\circ} \mathrm{C}$. The amplified PCR product size of 491 base pairs was digested by using restriction enzyme Pvull after overnight at $37^{\circ} \mathrm{C}$. Products were segregated by using $2.5 \%$ agarose gel electrophoresis. The polymorphic $1347 \mathrm{~A}$ allele paucity at restriction site; hence 491 bp PCR product was not divided. However, G allele had a restriction site which gave fragments of 313 and $178 \mathrm{bp}$ after the digestion (Figure 1).

\section{Statistical analysis}

Frequency distribution of genotypes according to HardyWeinberg equilibrium (HWE) was done by chi-square test. Association between the risk of IS and gen polymorphism was evaluated by Odds Ratio (OR) with $95 \%$ confidence intervals (Cls) by using conditional logistic regression analysis. Multivariate conditional logistic regression used for independent impact of SNP G1347A with risk of IS. Statistical significance was considered as $p<0.05$. STATA version 13.0 (StataCorp, 2013. Stata Statistical Software: Release 13. College Station, TX: StataCorp LP) was utilised for qualitative and quantitative data analysis.

\section{Results}

Mean age of controls was $50.97 \pm 12.70$ years and $52.83 \pm 12.59$ years for IS cases. Total 203 male and 47 females were in both groups. We did not observe statistically significant difference in age between patients and controls. Demographic variables and risk factor for both groups have been given in Table 1. Various risk factors significantly higher in IS than in controls (hypertension in $58.4 \%$, Diabetes in $31.6 \%$ and dyslipidemia in $22.8 \%$ of IS and in the control group, hypertension in $16.8 \%$, diabetes in $10.8 \%$ and $5.6 \%$ were dyslipidemia).

Genetic analysis of CYP4F2 G1347A was detected in all cases and controls. Tables $\mathbf{2}$ and $\mathbf{3}$ showing the distribution of genotypic and allelic frequencies between IS patients and controls. Frequency distribution was accordance with HWE in both groups. Significant relationship was detected in subjects carrying variation at 1347 location of CYP450 gene and risk of IS (Odds ratio, 1.7 with $95 \%$ $\mathrm{Cl}, 1.19-2.53 ; \mathrm{P}=0.004)$ under the dominant model of inheritance and (Odds ratio, 1.45 with $95 \% \mathrm{Cl}, 1.12-1.87 ; \mathrm{P}=0.003$ ) under allelic model. Significant association persisted even after adjustment of key confounding variables (Odds ratio, 2.05 with $95 \% \mathrm{Cl}, 1.18-3.56 ; \mathrm{P}=0.01$ ) in the dominant model. Our subgroup analysis based on TOAST classification indicated that increase in risk of Large Vessel Disease (LVD) for the carrier of CYP4F2 gene

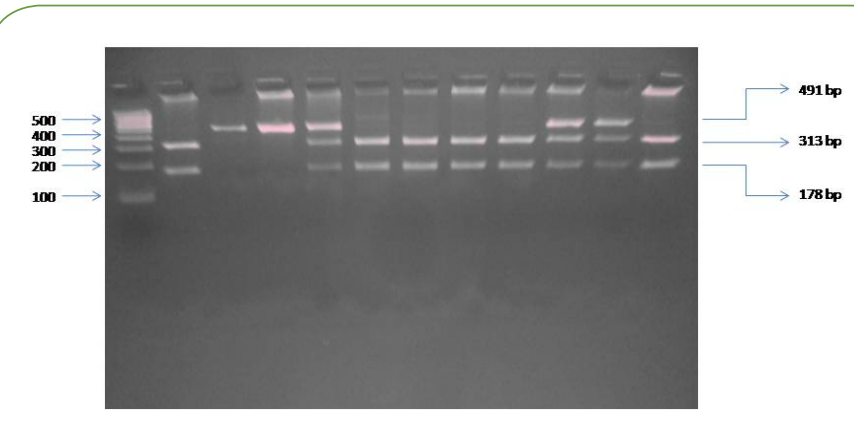

Figure 1 Gel image of PCR-RFLP of CYP4F2 G1347A gene polymorphism. 
Table 1 Demographic and risk factor variables for ischemic stroke (IS) patients and control subjects.

\begin{tabular}{|c|c|c|c|c|}
\hline Characteristics & Controls ( $\mathrm{N}=\mathbf{2 5 0}$ ) n (\%) & Ischemic stroke ( $\mathrm{N}=250)$ n (\%) & Crude OR [95\% Cl], p value & $\begin{array}{c}\text { *Adjusted OR }[95 \% \mathrm{Cl}], \mathrm{p} \\
\text { value }\end{array}$ \\
\hline Age in years (Mean \pm S.D) & $52.83 \pm 12.59$ & $50.97 \pm 12.70$ & \multirow{2}{*}{\multicolumn{2}{|c|}{ Matched }} \\
\hline Male/Female, $\mathrm{n}$ & $203 / 47$ & $203 / 47$ & & \\
\hline Hypertension & $42(16.8)$ & $146(58.4)$ & $8.4[4.8$ to 14.6$],<0.0001$ & $6.2[3.2$ to 12$],<0.0001$ \\
\hline Diabetes & $26(10.4)$ & $79(31.6)$ & $3.5[2.1$ to 5.7$],<0.0001$ & 2.1 [1.1 to 4.2 ], 0.02 \\
\hline Dyslipidemia & $14(5.6)$ & $57(22.8)$ & $5.2[2.6$ to 10.4$],<0.0001$ & $2.4[1.0$ to 5.7$], 0.04$ \\
\hline Smoking & $67(26.8)$ & $97(38.8)$ & $1.7[1.1$ to 2.5$], 0.005$ & 1.1 [0.6 to1.9], 0.69 \\
\hline Alcohol & $56(22.4)$ & $81(32.4)$ & 1.8 [1.1 to 2.8$], 0.008$ & 1.8 [0.9 to 3.5$], 0.05$ \\
\hline Myocardial Infarction & $4(1.6)$ & $17(6.8)$ & 5.3 [1.5 to 18.3$], 0.008$ & 1.8 [0.4 to 7.1$], 0.36$ \\
\hline Migraine with Aura & $8(3.2)$ & $10(4)$ & 1.2 [0.4 to 3.1$], 0.63$ & 1.6 [0.4 to 5.8$], 0.40$ \\
\hline Migraine without Aura & $4(1.6)$ & $5(2)$ & $1.2[0.3$ to 4.6$], 0.33$ & 1.3 [0.1 to 10.9$], 0.78$ \\
\hline Low Socioeconomic Status & $14(5.6)$ & $66(26.4)$ & $5.0[2.7$ to 9.0$],<0.0001$ & $7.5[3.0$ to 18.2$],<0.0001$ \\
\hline High BMI & $89(35.6)$ & 77 (30.8) & 0.7 [0.4 to 1.0$], 0.11$ & 0.8 [0.4 to 1.4$], 0.50$ \\
\hline Sedentary Life Style & $106(42.4)$ & $127(50.8)$ & 1.4 [1.0 to 2.1$], 0.04$ & 1.1 [0.6 to 1.9$], 0.6$ \\
\hline Physical activity & $136(54.4)$ & $107(42.8)$ & $0.6[0.4$ to 0.8$], 0.009$ & 0.7 [0.4 to 1.3$], 0.36$ \\
\hline Family history of stroke & $9(3.6)$ & $32(12.8)$ & 3.5 [1.6 to 7.4$], 0.001$ & 6.8 [2.2 to 20.9$], 0.001$ \\
\hline Family history of diabetes & $28(11.2)$ & $48(19.2)$ & 1.8 [1.1 to 3.1$], 0.015$ & $3.1[1.4$ to 6.9$], 0.004$ \\
\hline $\begin{array}{l}\text { Family history of } \\
\text { hypertension }\end{array}$ & $34(13.6)$ & $61(24.4)$ & $2.0[1.2$ to 3.1$], 0.003$ & 1.8 [0.9 to 3.4$], 0.06$ \\
\hline $\begin{array}{c}\text { Family history of heart } \\
\text { Attack }\end{array}$ & $14(5.6)$ & $19(7.6)$ & 1.4 [0.6 to 3.1 ], 0.33 & 1.7 [0.5 to 5.9 ], 0.38 \\
\hline
\end{tabular}

Conditional Logistic Regression Analysis: *Adjusted variables include Hypertension, Diabetes, Dyslipidemia, Smoking, Family History of stroke, Alcohol, Sedentary Life Style and Low socioeconomic status

Abbreviations: BMI: Body Mass Index; OR: Odds Ratio; Cl: Confidence Interval; SD: Standard Deviation

Table 2 Genotype and allelic frequencies of Cytochrome P450 (CYP4F2) G1347A gene polymorphism in ischemic stroke patients and controls.

\begin{tabular}{|c|c|c|c|c|c|c|c|c|c|c|}
\hline \multirow{2}{*}{ Group } & \multirow{2}{*}{ No. } & \multicolumn{3}{|c|}{ Genotypes n (\%) } & \multirow{2}{*}{ HWE $p$ value } & \multicolumn{2}{|c|}{ Allele $n(\%)$} & \multicolumn{3}{|c|}{ Allele G vs. A } \\
\hline & & GG & GA & AA & & G & A & OR & $95 \% \mathrm{Cl}$ & P value \\
\hline Con & 250 & 105 & 111 & 34 & 0.58 & 321 & 179 & & & \\
\hline IS & 250 & 73 & 130 & 47 & 0.41 & 276 & 224 & 1.45 & $1.12-1.87$ & 0.003 \\
\hline LVD & 107 & 24 & 62 & 21 & 0.09 & 110 & 104 & 1.69 & $1.22-2.34$ & 0.001 \\
\hline SVD & 83 & 30 & 35 & 18 & 0.20 & 95 & 71 & 1.34 & $0.93-1.91$ & 0.10 \\
\hline CE & 26 & 6 & 17 & 3 & 0.09 & 29 & 23 & 1.42 & $0.79-2.53$ & 0.23 \\
\hline Others & 34 & 13 & 16 & 5 & 0.98 & 42 & 26 & 1.11 & $0.65-1.87$ & 0.69 \\
\hline
\end{tabular}

Abbreviations: Con: Controls; Cl: Confidence Interval; G: Guanine; GG: Guanine Guanine; A: Adenine; GA: Guanine Adenine; AA: Adenine Adenine; IS: Ischemic Stroke; LVD: Large Vessel Disease; SVD: Small Vessel Disease; CE: Cardio Embolic; OR: Odds Ratio; HWE: Hardy Weinberg Equilibrium $* \mathrm{P}<0.05$ is considered as statistically significant.

Table 3 Association between Cytochrome P450 (CYP4F2) G1347A gene polymorphism and risk of ischemic stroke.

\begin{tabular}{|c|c|c|c|c|c|c|c|}
\hline Sample & $\mathbf{N}$ & Variants $\mathbf{n}(\%)$ & $\begin{array}{c}\text { Dominant Model } \\
\text { GA+AA vs. GG } \\
\text { Crude OR [95\% Cl], } \\
\text { p value }\end{array}$ & $\begin{array}{l}\text { Dominant Model } \\
\text { GA+AA vs. GG } \\
\text { **Adjusted OR [95\% } \\
\text { Cl], p value }\end{array}$ & Variants n (\%) & $\begin{array}{c}\text { Recessive Model AA } \\
\text { vs. GA+GG } \\
\text { Crude OR [95\% Cl], p } \\
\text { value }\end{array}$ & $\begin{array}{l}\text { Recessive Model AA } \\
\text { vs. GA+GG } \\
\text { **Adjusted OR [95\% } \\
\text { Cl], p value }\end{array}$ \\
\hline Controls & 250 & 145 & & & 34 & & \\
\hline IS & 250 & 177 & $\begin{array}{c}1.74(1.19-2.53), \\
0.004\end{array}$ & $2.05(1.18-3.56), 0.01$ & 47 & $1.5(0.91-2.46), 0.10$ & $1.72(0.84-3.49), 0.13$ \\
\hline LVD & 107 & 83 & $\begin{array}{c}2.50(1.49-4.20) \\
0.001\end{array}$ & $\begin{array}{c}3.32(1.72-6.43), \\
<0.001\end{array}$ & 21 & $1.55(0.85-2.82), 0.15$ & $1.51(0.72-3.16), 0.26$ \\
\hline SVD & 83 & 53 & $1.27(0.76-2.13), 0.34$ & $1.28(0.69-2.37), 0.42$ & 18 & $1.75(0.93-3.31), 0.08$ & $2.43(1.14-5.16), 0.02$ \\
\hline CE & 26 & 20 & $2.41(0.93-6.21), 0.06$ & $2.05(0.68-6.13), 0.19$ & 3 & $0.82(0.23-2.91), 0.76$ & $1.04(0.25-4.26), 0.95$ \\
\hline Others & 34 & 21 & $1.16(0.56-2.44), 0.67$ & 1.94 (0.76-4.93), 0.16 & 5 & $1.09(0.39-3.02), 0.86$ & $1.34(0.40-4.47), 0.62$ \\
\hline
\end{tabular}

Abbreviations: Con: Controls; Cl: Confidence Interval; G: Guanine; GG: Guanine Guanine; A: Adenine; GA: Guanine Adenine; AA: Adenine Adenine; IS: Ischemic Stroke; LVD: Large Vessel Disease; SVD: Small Vessel Disease; CE: Cardio Embolic; OR: Odds Ratio; HWE: Hardy Weinberg Equilibrium. ${ }^{*} \mathrm{P}<0.05$ is considered as statistically significant

**Adjusted analysis was done by adjusting hypertension, diabetes, dyslipidemia, smoking, family stroke record, alcohol, sedentary life style, low economic status variables. 
polymorphism unadjusted (Odds ratio 2.5 with $95 \% \mathrm{Cl}, 1.49-4.20$; $\mathrm{P}<0.001$ ) and adjusted (Odds ratio 3.32 with $95 \% \mathrm{Cl}, 1.72-6.43$ : $\mathrm{P}<0.001)$ analysis under the dominant model and also under the allelic model (Odds ratio 1.69 with 95\% Cl, 1.22-2.34; $\mathrm{P}<0.001$ ). Multivariable analysis also demonstrated a statistically significant relationship of CYP4F2 variant with risk of Small Vessel Disease (SVD) (Odds ratio, 2.43 with $95 \% \mathrm{Cl}, 1.14-5.16 ; \mathrm{P}=0.02$ ) under the recessive model.

\section{Discussion}

In this study Cytochrome $P 450$ gene polymorphism is associated with the risk of ischemic stroke mainly for the LVD. Several reports have shown a significant relationship of CYP4F2 polymorphism with the increase risk of IS $[16,17]$. A published meta-analysis by Meng et al. which included six studies with total 2187 case and 7556 controls, also shown a significant association with CYP450 variant and increase risk of IS under the recessive model (OR 1.37; 95\% Cl, 1.21-1.54; p<0.001) [10]. However, in case of hypertension a meta-analysis failed to observe a significant relationship of polymorphism G1347A and risk of IS [18]. An earlier reported study by Ward et al. [19] detected a positive correlation between CYP4F2 GA/AA polymorphism and both systolic blood pressure and increased excretion of 20-HETE which support the role of 29-HETE in regulation of blood pressure. Fava et al. also showed an association between A allele of 1347G/A SNP with risk of IS [16].

The findings of this present study were consistent with the results of the study reported from South Indian population [20] which also demonstrated that 1347A allele of CYP4F2 gene polymorphism is a significant risk factor of IS. Because etiology of IS heterogeneous therefore, genetic factors may vary by etiological subtypes of stroke. Evidence from literature has confirmed the association of genetic variants in specific subtypes of stroke [21]. In the present study, subgroup analysis according to TOAST classification suggested that A allele and AA genotype of gene CYP450 (G1347A) were associated significantly with LVD subtype of IS under the dominant model and with the

\section{References}

1 Krishnamurthi RV, Feigin VL, Forouzanfar MH, Mensah GA, Connor M, et al. (2013) Global and regional burden of first-ever ischaemic and haemorrhagic stroke during 1990-2010: Findings from the Global Burden of Disease Study 2010. Lancet Glob Health 1: e259-e281.

2 Bak S, Gaist D, Sindrup SH, Skytthe A, Christensen K (2002) Genetic liability in stroke: A long-term follow-up study of Danish twins. Stroke 33: 769-774.

3 Bevan S, Traylor M, Adib-Samii P, Malik R, Paul NLM, et al. (2012) Genetic heritability of ischemic stroke and the contribution of previously reported candidate gene and genome wide associations. Stroke J Cereb Circ 43: 3161-3167.

4 Patnala R, Clements J, Batra J (2013) Candidate gene association studies: A comprehensive guide to useful in silico tools. BMC Genet 14: 39.
SVD subtype of IS under recessive model of inheritance. In the subgroup analysis according to TOAST classification, Munshi et al. have shown a borderline significant relationship $(P=0.07)$ between $1347 \mathrm{~A}$ polymorphism of CYP4F2 and risk of intracranial large artery stroke [20]. These findings strengthen the role of Cytochrome $P 450$ (1347 G/A) in the mechanism of LVD subtype of ischemic stroke. In this study sample size was small to rule out type-II error associated with the present study results. Welldesigned prospective cohort studies are needed to corroborate the findings observed in the current study.

\section{Conclusion}

This study reveals that CYP4F2 (G1347A) gene variant might be a significant risk factor for IS mainly for LVD subtype of stroke in the North Indian population. It could be used as a potential genetic marker for screening the subjects with the risk of having IS particularly the LVD subtype of IS. We suggest more comprehensive prospective study involving multiple centres with large number of samples to validate the present findings.

\section{Acknowledgements}

- We acknowledge the technical assistance of staff members of the Neurology Department of All India Institute of Medical Sciences, New Delhi. We also thank all patients and controls participants for providing blood samples.

- We would like to thank Department of Biotechnology, Government of India for providing resources through the Programme support in stroke - Phase II projects for successfully completing this study.

\section{Funding}

Indian Council of Medical research, New Delhi, India (Ref No-5/45/76/Neuro/2012/NCD-1).

\section{Conflict of Interest}

The authors have declared that no competing interests exist.

5 Miyata N, Roman RJ (2005) Role of 20-hydroxyeicosatetraenoic acid (20-HETE) in vascular system. J Smooth Muscle Res Nihon Heikatsukin Gakkai Kikanshi 41: 175-193.

6 Yousif MHM, Benter IF, Dunn KMJ, Dahly-Vernon AJ, Akhtar S, et al. (2009) Role of 20-hydroxyeicosatetraenoic acid in altering vascular reactivity in diabetes. Auton Autacoid Pharmacol 29: 1-12.

7 Gebremedhin D, Lange AR, Lowry TF, Taheri MR, Birks EK, et al. (2000) Production of 20-HETE and its role in autoregulation of cerebral blood flow. Circ Res 87: 60-65.

8 Gebremedhin D, Yamaura K, Harder DR (2008) Role of 20-HETE in the hypoxia-induced activation of $\mathrm{Ca}^{2+}$-activated $\mathrm{K}^{+}$channel currents in rat cerebral arterial muscle cells. Am J Physiol Heart Circ Physiol 294: H107-H120.

9 Omura T, Tanaka Y, Miyata N, Koizumi C, Sakurai T, et al. (2006) Effect of a new inhibitor of the synthesis of 20-HETE on cerebral ischemia reperfusion injury. Stroke 37: 1307-1313. 
10 Meng C, Wang J, Ge WN, Tang SC, Xu GM (2015) Correlation between CYP4F2 gene rs2108622 polymorphism and susceptibility to ischemic stroke. Int J Clin Exp Med 8: 16122-16126.

11 Kumar P, Kumar A, Misra S, Sagar R, Faruq M, et al. (2016) Tumor necrosis factor-alpha $(-308 \mathrm{G} / \mathrm{A},+488 \mathrm{G} / \mathrm{A},-857 \mathrm{C} / \mathrm{T}$ and $-1031 \mathrm{~T} / \mathrm{C})$ gene polymorphisms and risk of ischemic stroke in north Indian population: A hospital based case-control study. Meta Gene 7: 3439.

12 Meschia JF, Lojacono MA, Miller MJ, Brott TG, Atkinson EJ, et al. (2004) Reliability of the questionnaire for verifying stroke-free status. Cerebrovasc Dis Basel Switz 17: 218-223.

13 Kumar P, Kumar A, Misra S, Sagar R, Farooq M, et al. (2016) Association of transforming growth factor- $\beta 1$ gene C509T, G800A and $\mathrm{T} 869 \mathrm{C}$ polymorphisms with intracerebral hemorrhage in North Indian Population: a case-control study. Neurol Sci Off J Ital Neurol Soc Ital Soc Clin Neurophysiol 37: 353-359.

14 Adams HP, Bendixen BH, Kappelle LJ, Biller J, Love BB, et al. (1993) Classification of subtype of acute ischemic stroke. Definitions for use in a multicenter clinical trial. TOAST. Trial of Org 10172 in Acute Stroke Treatment. Stroke J Cereb Circ 24: 35-41.

15 Kumar A, Sagar R, Kumar P, Sahu JK, Grover A, et al. (2013) Identification of genetic contribution to ischemic stroke by screening of single nucleotide polymorphisms in stroke patients by using a case control study design. BMC Neurol 13: 136.
16 Fava C, Montagnana M, Almgren P, Rosberg L, Lippi G, et al. (2008) The V433M variant of the CYP4F2 is associated with ischemic stroke in male Swedes beyond its effect on blood pressure. Hypertension 52: $373-380$.

17 Deng S, Zhu G, Liu F, Zhang H, Qin X, et al. (2010) CYP4F2 gene V433M polymorphism is associated with ischemic stroke in the male Northern Chinese Han population. Prog Neuropsychopharmacol Biol Psychiatry 34: 664-668.

18 Luo XH, Li GR, Li HY (2015) Association of the CYP4F2 rs2108622 genetic polymorphism with hypertension: a meta-analysis. Genet Mol Res GMR 14: 15133-15139.

19 Ward NC, Tsai IJ, Barden A, Van Bockxmeer FM, Puddey IB, et al. (2008) A single nucleotide polymorphism in the CYP4F2 but not CYP4A11 gene is associated with increased 20-HETE excretion and blood pressure. Hypertension 51: 1393-1398.

20 Munshi A, Sharma V, Kaul S, Al-Hazzani A, Alshatwi AA, et al. (2012) Association of 1347 G/A cytochrome P450 4F2 (CYP4F2) gene variant with hypertension and stroke. Mol Biol Rep 39: 1677-1682.

21 Bellenguez C, Bevan S, Gschwendtner A, Spencer CCA (2012) International Stroke Genetics Consortium (ISGC). Wellcome Trust Case Control Consortium 2 (WTCCC2). Genome-wide association study identifies a variant in HDAC9 associated with large vessel ischemic stroke. Nat Genet 44: 328-333. 